\title{
Analyzing Malnutrition Among Children of Urban Areas in Bangladesh: Penalized Logistic Regression Model
}

\author{
Naito Kanon and Wasimul Bari* \\ Department of Statistics, University of Dhaka, Dhaka-1000, Bangladesh
}

(Received : 25 March 2019 ; Accepted :7 January 2020)

\begin{abstract}
This paper focused on the analysis of malnutrition of the children of Bangladesh urban areas in the presence of multicollinearity among the covariates. The ridge regression has been adopted under binary logistic model for analyzing malnutrition data extracted from Bangladesh Urban Health Survey 2013 (UHS 2013) dataset. The study reveals that city corporation slum area, mother's age at birth, gender of child, birth order number, age of child, wealth index, mother's education, access to media, toilet facility at household, taking antenatal care service, and place of delivery of index child have significant impact on the nutritional status of urban children of Bangladesh. Some recommendations have been suggested for policy makers to improve the child health of urban areas in Bangladesh.
\end{abstract}

Keywords: Logistic regression model, Malnutrition, Multicollinearity, Slum area, Urban Health Survey

\section{Introduction}

Child malnutrition, a major challenging issue in many developing countries, has been one of the leading public health problems in Bangladesh now-a-days. Child malnutrition is the consequence of collection of factors which includes poor food quality, insufficient food intake and early childhood infectious diseases ${ }^{1}$. Malnutrition is not only the major cause of illness and child mortality, it has adverse effects on cognitive development and physical health of children at early stage of growth ${ }^{2}$. This cognitive and physical deficits have generation consequences since malnourished mothers are supposed to give birth to lowbirth-weight infants ${ }^{3}$. During the last few years, Bangladesh has witnessed impressive progress in health and nutrition. According to the report of BDHS 1996-97 and 2014, the prevalence of malnutrition, stunting, among under five children was $60 \%$ in 1996-97, while in 2014 it decreased to $36 \%^{4-5}$. In spite of substantial progress in terms of reducing malnutrition, prevalence rate of malnourished children in Bangladesh is still exceedingly high according to benchmark set by World Health Organization (WHO) ${ }^{6}$.

Bangladesh has experienced a remarkable improvement in the process of urbanization since its independence. Urbanization is an inevitable feature in the process of development of an economy, which is frequently used as an indicator of a country's entire development. The process of urbanization refers to the shift in population from rural to urban areas, the gradual increase in the size of urban population and the extent of urban areas? Urbanization is certainly providing great opportunities for overall economic prosperity of a country, however at the same time it is arising formidable challenges to social equity and environmental sustainability. Some of the challenging issues associated with urbanization are high population density, inadequate infrastructure, slum creation, pollution, hygiene, sanitation, malnutrition and poverty. A study conducted in countries of Asia, Africa and Latin America by Demographic and Health Surveys reveals that the infant and children of slum areas have greater incidence of diarrheal illness and are less likely to survive till their fifth birthdays ${ }^{8}$. Rapid urbanization also arises the challenge of income inequalities, which manifests in food insecurity and consequently child malnutrition. The urban children of the lowest socioeconomic class in some Latin America countries had up to 10 times the risk of being stunted compared to the children of higher socio-economic class ${ }^{9}$.

An extensive literature review reveals that average children nutrition outcomes in the urban areas are remarkably better than in the rural areas, that is, urban children possess better nutritional condition compared to their rural counterparts ${ }^{9}$ 10. According to Bangladesh Urban Health Survey 2013 report, half of all the under five children in urban slums were found to be malnourished, which was an unsatisfactory outcome ${ }^{11}$. Therefore, the prevalence of malnutrition among the urban children remains a challenging obstacle that needs to be overcome.

Previous studies disclosed that different socio-economic, demographic and maternal health related factors are common determinants of child malnutrition. Islam and Biswas conducted a situation analysis and examined the impact of socio-economic covariates on chronic malnutrition-stunting among under five children in Bangladesh; mother's educational status and wealth index were found strongly associated with stunting ${ }^{12}$. Khan and Raza used binary logistic regression analysis to identify potential factors responsible for malnutrition among under 5 children in rural and urban areas of Bangladesh ${ }^{13}$. Srinivashan et al. attempted to reveal the rural-urban discrepancies in child nutrition outcomes in Bangladesh applying quantile regression model ${ }^{10}$. Das and Gulshan conducted an empirical study to investigate the extent of malnutrition, which showed that age of children, type of residence, mother's education, occupation, birth order, wealth index, toilet facility, mother's BMI, and number of living children were found to be contributing factors of stunting ${ }^{14}$. Talukder applied proportional odds (PO) model to identify the influential factors associated

*Author for correspondence. e-mail: w_bari@du.ac.bd 
with malnutrition of under five children in Bangladesh using BDHS 2014 dataset. The study pointed out that mother's and father's education, mother's BMI, wealth index, and ANC service during pregnancy had significant impact on malnutrition status ${ }^{15}$.

No study has been found in literature that addressed the multicollinearity problem in analyzing the data to find out potential determinants of malnutrition status of children in Bangladesh. The principal purpose of this paper is to determine the factors that are responsible for malnutrition among the children of urban areas of Bangladesh in the presence of multicollinearity among the covariates. For this purpose, data extracted from Bangladesh Urban Health Survey 2013 (UHS 2013) have been used. Multicollinearity is a common statistical phenomenon, which often arises when the inter-correlated covariates are dealt in statistical models. The presence of multicollinearity makes it difficult to determine the relative impact of the estimated coefficients significantly. Hence, it is important for a researcher to overcome the problem of multicollinearity for drawing a plausible inference through using an appropriate regression model. In this study, the approach of variance inflation factor (VIF) has been used for the detection of multicollinearity among the regressors. Ridge logistic regression model has been employed to assess the impacts of a set of covariates on nutritional status of children of urban areas of Bangladesh.

This paper is structured as follows. In section 2, a short description of Bangladesh Urban Health Survey 2013 data and methodology are presented, including the description of outcome and explanatory variables used in this study. The results obtained from the univariate, bivariate and ridge logistic regression analyses are presented in section 3 . The concluding remarks with the findings of the study are discussed in section 4 .

\section{Data and Methods}

\section{Data}

This study has utilized data extracted from Bangladesh Urban Health Survey (UHS), 2013 for analyzing malnutrition status among children of urban areas of Bangladesh. The UHS, 2013 was implemented under the authority of the National Institute of Population Research and Training (NIPORT), International Centre for Diarrhoeal Disease Research, Bangladesh (ICDDR,B), MEASURE Evaluation, University of North Carolina at Chapel Hill, USA and the Associates for Community and Population Research (ACPR). This survey was designed to collect data on communities, households and individuals throughout the city corporation areas, municipalities and large towns with population over 45,000 . This survey followed a 3-stage stratified sampling procedure where the strata were divided as (1) city corporations: slum and nonslum; and (2) rest of urban areas (district municipalities and large towns). In the first stage of selection, 450 mohollas were selected randomly from city corporations and 184 were selected from other urban areas. The second stage of selection consisted of randomly selecting two non-slum clusters and one slum cluster from each of the selected mohollas chosen in the first stage of selection. In the third stage, a household listing activity was carried out in each selected clusters, where 30 and 35 household were selected from each of the non-slum and slum clusters, respectively. All ever-married women of age 15-49 years and all evermarried men age of 15-54 years were interviewed in this survey.

The main goal of this paper is to find out a set of potential socio-economic, demographic and maternal health related determinants of malnutrition among the children of urban areas of Bangladesh. Traditionally, malnutrition is measured by three anthropometric indices. These are stunting (height-for-age), wasting (weight-for-height) and underweight (weight-for-age). Among these three indices, stunting reflects the effects of malnutrition and infectious diseases since and even before birth. This measure also reflects long-term outcomes such as frequent and high disease burden or poor feeding practices or low household socio-economic condition in the target population ${ }^{6}$. Because of this reason, this study considered stunting as outcome variable to investigate the malnutrition status among the children of urban areas of Bangladesh.

\section{Response variable}

In this study, the response variable, stunting, is defined as binary random variable using height-for-age $\mathrm{Z}(\mathrm{HAZ})$ score. If the HAZ score for a child is less than minus two standard deviation ( -2 SD) below the mean of the standard population, the child is considered as stunned, otherwise not. Mathematically, Z-score is defined as Z-score= (individual height- mean value of standard population)/standard deviation value of standard population. This Z-score has been calculated using WHO Anthro software by taking children's gender, age, height (centimeters) and weight (kilograms) into account.

\section{Covariates}

On the basis of literature, 18 categorical covariates are considered in this study to determine the influential factors of stunting. The covariates considered in this study are: Domain (Slum, Non-slum, Rest Urban), Birth order number $\left(1^{\text {st }}, 2^{\text {nd }}\right.$ to $3^{\text {rd }}$, Above $\left.3^{\text {rd }}\right)$, Gender of child (Girl, Boy), Age of Child (in months) $(<12,12-23,>23)$, Mother's age at birth $(<20,20-30,>30)$, Wealth index (Poor, Middle, Rich), Mother's educational status (No Education, Primary, Secondary, Higher), Mother's working status (Not-working, Working), Mother's NGO membership (Non-member, Member), Access to media (Unexposed, Exposed), Migration (Migrant, Non-migrant), Antenatal care (ANC) Service (Yes, No), Source of drinking water (Unimproved, Improved), Toilet facility (Unimproved, Improved), Main material of floor (Unimproved, Improved), Type of fuel (Clean, Polluting), Garbage disposal (Inside, Outside) and Place of delivery (Home, Hospital/Clinic). 
For the purpose of analysis, children who born preceding 3 years of the survey have only been considered. A total of 7879 children were chosen in this study who had complete information on the selected socioeconomic, demographic and maternal health related characteristics.

\section{Detection of Multicollinearity}

Variance inflation factor (VIF) is the most widely used approach for detecting multicollinearity. This factor quantifies how much higher the variance are when covariates are correlated compared to when they are uncorrelated $^{16}$. Suppose that the set of covariates are $X_{1}, X_{2}, \ldots, X_{p}$. The variance inflation factor for $j^{t h}$ explanatory variable is then defined as

$$
(V I F)_{j}=\left[1-R_{j}^{2}\right]^{-1} ; \quad j=1,2, \ldots, p,
$$

where $R_{j}^{2}$ denotes the coefficient of determination obtained by regressing $X_{j}$ on the remaining $(p-1)$ variables excluding $X_{j}$. Value of VIF greater than 10 often indicates the existence of multicollinearity; but most often specially in the case of logistic regression model values exceeding 2.5 suggests a cause of concern ${ }^{17-18}$.

\section{Penalized Regression}

Penalized regression is a shrinkage method, which has been commonly used when the regression model is affected with multicollinearity ${ }^{19}$. This regression technique imposes a restriction on regression coefficient that causes the coefficients of the less contributive variables to shrink toward zero. If we consider an arbitrary parametric model with parameter vector $\beta$ and $\log$-likelihood function $l(\beta)$, then the penalized likelihood estimator of $\beta$ maximized the penalized log-likelihood function defined as

$$
l_{p}(\beta)=l(\beta)-\lambda \operatorname{Pen}(\beta),
$$

where $\operatorname{Pen}(\cdot)$ is a penalty function and $\lambda>0$ is a penalization parameter, which controls the strength of penalty term. In this study, L2-penalized (also known as ridge) logistic regression model has been used for overcoming the multicollinearity situation. Ridge regression considers the squared L2-norm penalty function, that is,

$$
\operatorname{Pen}(\beta)=\sum_{j=1}^{p} \beta_{j}^{2}=\beta^{\prime} \beta
$$

Therefore, in the ridge logistic regression set-up, the regression coefficients $\beta_{1}, \beta_{2}, \ldots, \beta_{p}$ are estimated by maximizing partial log-likelihood function, where the penalty function is subtracted from the log-likelihood function obtained under logistic regression model. Note that under ridge regression, each column of covariate matrix is centered and standardized as restriction on the regression coefficient is imposed. For the analysis purpose, R 3.5.0 has been used in this study. The detection of multicollinearity and ridge regression analysis were conducted using mctest and ridge packages, respectively.

\section{Results}

In this study, univariate, bivariate and regression analyses have been performed. Table 1 represents percentage distribution of stunting in terms of selected demographic, socio-economic and maternal health related variable.

Table 1. Percentage distribution of stunting by selected demographic, socio-economic and maternal

\begin{tabular}{|c|c|c|c|c|}
\hline \multirow[t]{2}{*}{ Covariates } & \multirow{2}{*}{\begin{tabular}{|c|}
$\begin{array}{c}\text { Percentage } \\
(\%)\end{array}$ \\
\end{tabular}} & \multicolumn{2}{|c|}{ Stunting } & \multirow[t]{2}{*}{ p-value } \\
\hline & & $\begin{array}{c}\text { Not- } \\
\text { Stunted }\end{array}$ & Stunted & \\
\hline \multicolumn{4}{|l|}{ Domain (7879) } & $<0.001$ \\
\hline Slum (3478) & 44.1 & 53.0 & 47.0 & \\
\hline Non-slum (1803) & 22.9 & 65.2 & 34.8 & \\
\hline Rest Urban (2598) & 33.0 & 62.6 & 37.4 & \\
\hline \multicolumn{4}{|c|}{ Mother's Age at Birth (7879) } & 0.036 \\
\hline$<20(2032)$ & 25.8 & 56.6 & 43.4 & \\
\hline $20-30(4671)$ & 59.3 & 60.0 & 40.0 & \\
\hline$>30(1176)$ & 14.9 & 59.2 & 40.8 & \\
\hline \multicolumn{4}{|c|}{ Gender of Child (7879) } & $<0.001$ \\
\hline Boy (3942) & 50.0 & 56.5 & 43.5 & \\
\hline Girl (3937) & 50.0 & 61.4 & 38.6 & \\
\hline \multicolumn{4}{|c|}{ Birth Order Number (7879) } & $<0.001$ \\
\hline $1^{\text {st }}(3180)$ & 40.4 & 61.1 & 38.9 & \\
\hline $2^{\text {nd }}-3^{\text {rd }}(3873)$ & 49.2 & 59.5 & 40.5 & \\
\hline Above $3^{\text {rd }}(826)$ & 10.5 & 48.7 & 51.3 & \\
\hline \multicolumn{4}{|c|}{ Age of Child (in month)(7879) } & $<0.001$ \\
\hline$<12$ & 27.1 & 73.1 & 26.9 & \\
\hline $12-23$ & 28.7 & 51.6 & 48.4 & \\
\hline$>23$ & 44.2 & 55.1 & 44.9 & \\
\hline \multicolumn{4}{|l|}{ Wealth Index (7879) } & $<0.001$ \\
\hline Poor $(4057)$ & 51.5 & 52.0 & 48.0 & \\
\hline Middle (1629) & 20.7 & 60.3 & 39.7 & \\
\hline Rich (2193) & 27.8 & 70.9 & 29.1 & \\
\hline \multicolumn{4}{|c|}{ Mother's Educational Status (7879) } & $<0.001$ \\
\hline No education (1230) & 15.6 & 48.5 & 51.5 & \\
\hline Primary (2365) & 30.0 & 51.3 & 48.7 & \\
\hline Secondary (3224) & 40.9 & 63.6 & 36.4 & \\
\hline Higher (1060) & 13.5 & 74.2 & 25.8 & \\
\hline \multicolumn{4}{|c|}{ Mother's Working Status (7879) } & $<0.001$ \\
\hline Working (1240) & 15.7 & 52.3 & 47.7 & \\
\hline Not-working (6639) & 84.3 & 60.2 & 39.8 & \\
\hline \multicolumn{4}{|l|}{ Migration (7879) } & 0.732 \\
\hline Migrant (613) & 7.80 & 59.7 & 40.3 & \\
\hline Non-migrant (7266) & 92.2 & 58.9 & 41.1 & \\
\hline \multicolumn{4}{|c|}{ Mother's NGO Membership (7879) } & 0.159 \\
\hline Member (1328) & 16.9 & 57.2 & 42.8 & \\
\hline Non-member (6551) & 83.1 & 59.3 & 40.7 & \\
\hline \multicolumn{4}{|c|}{ Access to Media (7879) } & $<0.001$ \\
\hline Exposed (6942) & 88.1 & 60.6 & 39.4 & \\
\hline Unexposed (937) & 11.9 & 47.3 & 52.7 & \\
\hline \multicolumn{4}{|c|}{ Source of Drinking Water (7879) } & 0.382 \\
\hline Improved (7846) & 99.6 & 59.0 & 41.0 & \\
\hline Unimproved (33) & 0.4 & 51.5 & 48.5 & \\
\hline \multicolumn{4}{|c|}{ Toilet Facility (7879) } & 0.008 \\
\hline Improved (6701) & 85.0 & 59.6 & 40.4 & \\
\hline Unimproved (1178) & 15.0 & 55.4 & 44.6 & \\
\hline \multicolumn{4}{|c|}{ Main Material of Floor (7879) } & $<0.001$ \\
\hline Improved (5924) & 75.2 & 61.1 & 38.9 & \\
\hline
\end{tabular}
health related variables along with p-values; UHS data $2013(n=7879)$ 


\begin{tabular}{|l|l|l|l|l|}
\hline Unimproved (1955) & 24.8 & 52.5 & 47.5 & \\
\hline Type of Fuel (7879) \\
\hline $\begin{array}{l}\text { Clean Fuel (4691) } \\
\text { Polluting Fuel } \\
(3188)\end{array}$ & 59.5 & 60.5 & 39.8 & \\
\hline Garbage Disposal (7879) & 57.2 & 42.8 & \\
\hline Inside (2828) & 35.9 & 60.7 & 39.3 & \\
Outside (5051) & 64.1 & 58.0 & 42.0 & \\
\hline ANC Service (7879) & 79.0 & 61.5 & 38.5 & \\
\hline Yes (6228) & 21.0 & 49.4 & 50.6 & \\
No (1651) & & & $<0.001$ \\
\hline Place of Delivery (7879) & 49.7 & 64.4 & 35.6 & \\
\hline Hospital/Clinic & 50.3 & 53.6 & 46.4 & \\
(3918) & & & \\
Home (3961) &
\end{tabular}

It is observed from Table 1 that the highest percentage of respondents was from slum areas $(44.1 \%)$, whereas lowest percentage of respondents was from non-slum areas (22.9\%). Among mothers, 59.3\% gave their birth, when they were in age group 20-30. Around half of the children were the second or the third child of their mothers. Only $27.1 \%$ of the children were infants. Highest percentage of respondents $(51.5 \%)$ were from poor families. It is noticed that very few women have completed their higher education $(13.5 \%)$. Highest percentage was observed for the women who completed secondary education (40.9\%). Only $15.7 \%$ of mothers were found to be employed and $7.8 \%$ of mothers were migrants. It is observed that $16.9 \%$ of mothers were the member of any non-governmental organizations (NGO) and $88.1 \%$ of respondents were found to be exposed to media. Most of the households $(85 \%)$ had improved toilet facility. Among the respondents, $59.5 \%$ of respondents made use of clean fuel for cooking and $79.0 \%$ of respondents reported that they took ANC service during their pregnant.

Since all of the selected covariates are categorical in nature, chi-square test has been used to study the association between all the selected covariates and response variable. These results are also reported in Table 1. All covariates except migration, mother's NGO membership, and source of drinking water were found to have significant association with stunting of children.

It is clear from Table 1 that highest percentage of stunted children (47\%) was from slum area, on the other hand, thelowest percentage was observed in non-slum area (34.8\%). A child was more likely $(43.4 \%)$ to be stunned if mother's age of index child was less than 20 years. The highest percentage of stunted children was aged between 12 to 23 months (48.4\%). The percentage of stunted children among poor families was comparatively high (48\%). It is noticed that the children of higher educated mothers were less likely to be stunted (25.8\%).The children of working women were more likely to be stunted $(47.7 \%)$. The mothers who were unexposed to media were more likely to have stunted children (52.7\%). Children from households having improved toilet facility and improved floor material were less likely to be stunted $(40.4 \%$ and $38.9 \%$, respectively). The children of the mothers using polluting fuel for cooking were more stunted $(42.8 \%)$ compared to the children of mother who used clean fuel $(39.8 \%)$. The women who received ANC service had less proportion of stunted children (38.5\%). Children delivered at home were more likely $(46.4 \%)$ to be stunted than those who were delivered at hospital/clinic (35.6\%).

The variables found to have significant association in bivariate analysis are considered in regression analysis. In this study, it is desired to examine the adjusted effects of covariates on response variable after controlling the effects of multicollinearity among the covariates. Therefore, before conducting regression analysis, multicollinearity diagnostics have been performed using the variance inflation factor among the covariates considered for regression analysis.

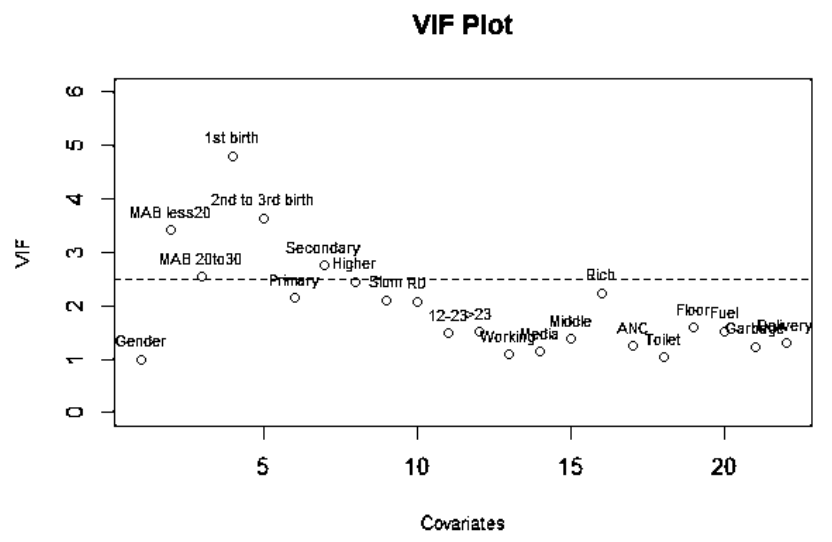

Fig 1. VIF plot for all individual diagnostic measure

Figure 1 depicts that multicollinearity exists among the regressors. Collinearity was detected in mother's age at birth less than 20and age at birth 20-30; $1^{\text {st }}$ birth and $2^{\text {nd }}$ $3^{\text {rd }}$ birth; and mother's secondary education as the VIF values corresponding these variables were found to be greater than 2.5 .

As the data of this study are afflicted with multicollinearity, ridge logistic regression is appropriate to examine the impact of selected covariates on response variable. Results obtained from the regression model were reported in Table 2.

Table 2. Estimates of regression coefficients along with scaled estimates, scaled standard error, odds ratio and $p$-values obtained from ridge logistic regression model; UHS data $2013(n=7879)$

\begin{tabular}{|c|c|c|c|c|c|}
\hline Covariates & Coefficients & $\begin{array}{c}\text { Est. } \\
\text { (scaled) }\end{array}$ & $\begin{array}{c}\text { S.E. } \\
\text { (scaled) }\end{array}$ & $\begin{array}{c}\text { Odds } \\
\text { Ratio }\end{array}$ & p-value \\
\hline Intercept & -0.134 & - & - & - & - \\
\hline $\begin{array}{c}\text { Domain } \\
\text { Non-slum }\end{array}$ & - & - & - & - & - \\
Slum & 0.114 & 5.035 & 1.967 & 1.121 & 0.010 \\
Rest Urban & -0.069 & -2.909 & 1.987 & 0.933 & 0.143 \\
\hline $\begin{array}{c}\text { Mother's Age at } \\
\text { Birth }\end{array}$ & - & - & & & \\
$<20$ & 0.091 & 3.552 & - & - & - \\
$20-30$ & 0.008 & 0.338 & 1.978 & 1.095 & 0.073 \\
$>30$ & - & - & - & - & - \\
\hline
\end{tabular}




\begin{tabular}{|c|c|c|c|c|c|}
\hline $\begin{array}{c}\text { Gender of Child } \\
\text { Girl } \\
\text { Boy } \\
\end{array}$ & $\begin{array}{c}- \\
0.172\end{array}$ & $\begin{array}{c}- \\
7.622\end{array}$ & $\begin{array}{c}- \\
1.757\end{array}$ & $\begin{array}{c}- \\
1.188\end{array}$ & $<0 . \overline{0}$ \\
\hline $\begin{array}{l}\text { Birth Order } \\
\text { Number }\end{array}$ & & & & & \\
\hline $1^{\mathrm{st}}$ & -0.126 & -5.478 & 1.940 & 0.882 & 0.005 \\
\hline $2^{\text {nd }}-3^{\text {rd }}$ & -0.095 & -4.229 & 1.946 & 0.909 & 0.029 \\
\hline Above $3^{\text {rd }}$ & - & - & - & - & - \\
\hline $\begin{array}{l}\text { Age of Child (in } \\
\text { month) }\end{array}$ & & & & & \\
\hline$<12$ & - & - & - & - & - \\
\hline $12-23$ & 0.656 & 26.338 & 1.885 & 1.927 & $<0.001$ \\
\hline$>23$ & 0.525 & 23.144 & 1.900 & 1.690 & $<0.001$ \\
\hline $\begin{array}{l}\text { Wealth Index } \\
\text { Poor }\end{array}$ & - & 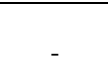 & - & - & - \\
\hline Middle & -0.072 & -2.589 & 1.819 & 0.931 & 0.155 \\
\hline Rich & -0.305 & -12.126 & 2.023 & 0.737 & $<0.001$ \\
\hline $\begin{array}{c}\text { Mother's } \\
\text { Education }\end{array}$ & & & & & \\
\hline No education & - & - & - & - & - \\
\hline Primary & 0.062 & 2.530 & 1.889 & 1.064 & 0.180 \\
\hline Secondary & -0.209 & -9.131 & 1.925 & 0.811 & $<0.001$ \\
\hline Higher & -0.418 & -12.665 & 1.974 & 0.658 & $<0.001$ \\
\hline Mother's & & & & & \\
\hline Working Status & - & - & - & - & - \\
\hline $\begin{array}{l}\text { Not-working } \\
\text { Working }\end{array}$ & 0.078 & 2.514 & 1.772 & 1.081 & 0.156 \\
\hline Access to Media & & & & & \\
\hline Unexposed & - & - & - & - & - \\
\hline Exposed & -0.219 & -6.295 & 1.778 & 0.803 & $<0.001$ \\
\hline Toilet Facility & & & & & \\
\hline Unimproved & - & - & - & - & - \\
\hline Improved & -0.103 & -3.258 & 1.760 & 0.902 & 0.064 \\
\hline $\begin{array}{l}\text { Main Material } \\
\text { of Floor }\end{array}$ & - & - & - & - & - \\
\hline $\begin{array}{l}\text { Improved } \\
\text { Unimproved }\end{array}$ & -0.076 & -2.907 & 1.911 & 0.927 & 0.128 \\
\hline Type of Fuel & & & & & \\
\hline Polluting & - & - & - & - & - \\
\hline Clean & 0.004 & 0.165 & 1.925 & 1.004 & 0.932 \\
\hline $\begin{array}{l}\text { Garbage } \\
\text { Disposal }\end{array}$ & & & & & \\
\hline Outside & - & - & - & - & - \\
\hline Inside & -0.018 & -0.769 & 1.844 & 0.982 & 0.676 \\
\hline ANC Service & & & & & \\
\hline No & - & - & - & - & - \\
\hline Yes & -0.142 & -5.122 & 1.821 & 0.868 & 0.005 \\
\hline $\begin{array}{l}\text { Place of } \\
\text { Delivery }\end{array}$ & & & & & \\
\hline Home & - & - & - & - & - \\
\hline Hospital & -0.103 & -4.571 & 1.859 & 0.902 & 0.014 \\
\hline
\end{tabular}

Table 2 reveals that domain, mother's age at birth, gender of child, age of child, birth order number, wealth index, mother's education, access to media, toilet facility, ANC service and place of delivery have significant association with stunting among children of urban areas (at least at $10 \%$ level of significance). It is noticed that children from slum area had $12.1 \%$ higher odds of being stunted in contrast to the children from non-slum area. The children whose mother's age at birth is less than 20 had $9.5 \%$ higher odds of remaining stunted compared to those children whose mother's age at birth is above 30 . It is found that a male child was more likely to be stunned compared to a female child $(\mathrm{OR}=1.188)$. The first child had $11.8 \%$ and second or third child had $9.1 \%$ lower odds of having stunting compared to a child of birth order above third. Children aged between 12 to 23 months had $92.7 \%$ and those who were above 23 months had $69 \%$ higher odds of being stunted compared to the children aged less than 12 months. Children from well off families were less $(\mathrm{OR}=0.737)$ prone to be stunned than children from families with the other economic conditions. It is observed from Table 2 that as education. level of mothers increases, the malnutrition status among children decreases. Children from secondary and higher educated mother had $18.9 \%$ and $34.2 \%$ lower odds of being stunted, respectively compared to the children of uneducated mother. A child whose mother was exposed to media had $19.7 \%$ lower odds of being stunted compared to a child whose mother was not exposed to media. It is noticed that children of household having improved toilet facility had $9.8 \%$ lower odd of being stunted compared to the children of household having unimproved toilet facility. The children whose mother received ANC service had 13.2\% lower odds of being stunted compared to the children whose mother did not receive ANC during her pregnancy period. A child born at hospital had $9.8 \%$ lower odds of being stunted compared to a child born at home.

\section{Discussion and Conclusion}

Though Bangladesh has witnessed remarkable progress in child nutrition, malnutrition of children is still a challenging issue, which poses a tremendous threat to any physical, mental and emotional development of children. This study examined the impacts of a set of selected covariates on nutritional status of children after controlling the effect of multicollinearity.

This study reveals the fact that the prevalence of stunting in slum children is relatively high as compared to the children of non-slum areas. The effect of rest-urban areas has insignificant impact on stunting, which implies that the children growing up in city corporation non-slum areas and other urban areas experience almost the same quality of life. Therefore, these findings suggest the unmet need of policies for the improvement of child health of slum areas in urban areas of Bangladesh.

Children are more likely to be stunned if his/her mother was in the lower age group at the time of delivery. This may happen because younger mothers are less conscious and less careful about proper child care and nutrition. This study revealed that prevalence of stunting in male children is higher as compared to the female children. Therefore, being a male child is identified as a risk factor of child malnutrition in urban areas. The percentage of stunted children is comparatively higher for the children aged above 12 months compared to the infants. This study also identified the significant association between the socioeconomic indicator wealth index and stunting. The children of poor as well as middle class families are more likely to remain stunted compared to the children of rich families. This finding is inconsistent with previous study ${ }^{14}$ conducted using data from Bangladesh. This may happen because the lifestyle and facilities experienced by the urban poor and middle class children are indistinguishable and so special 
attention should be paid on the children of urban poor and middle class families so that they get easier access to quality health care services and proper child care. This study found that children from illiterate and primary educated mother are more likely to be stunted in comparison with their counterparts, which implies that illiteracy and primary education are indifferent to provide knowledge regarding maternal health education. Therefore, maternal health education should be more emphasized in primary education.

Birth order number of index child is found to be a risk factor of stunting among the urban children. The proportion of stunted children is relatively high for children whose birth order number is above 3 . This may happen due to the fact that children of higher birth order get relatively less attention of their parents. A mother who is exposed to media is less likely to have stunted children. This is because mass media has powerful role in promoting knowledge and consciousness regarding maternal as well as child health and nutrition.

Presence of improved toilet facility is found as a vital factor associated with stunting. Children from households with improved toilet facility are less likely to be stunted. This is because unimproved toilet often causes diarrheal related diseases, which prevent children's body from absorbing nutrients and consequently children become malnourished. In addition, it is found that mothers who received antenatal care service during pregnancy are less likely to have stunted children. This study also reveals that children born at hospital are less likely to be stunted. The findings of the analysis suggests that in order to improve the nutrition status of urban children of Bangladesh, proper steps need to be taken highlighting the children of city corporation slum areas and urban poor and middle class families.

The main strength of this paper over other studies dealing with the same topic is that multicollinearity among predictors has been taken into account in analyzing data to find out adjusted influence of selected covariates on the nutritional status of children of urban areas of Bangladesh. This study has also examined the impacts of covariates without taking the effect of multicollinearity into account and it was found that the results attained from two different models were distinguishable. The impact of domain and place of delivery on nutritional status of children were not found significant, when the effect of multicollinearity was not controlled. Since data used for the purpose analysis were obtained through a cross-sectional study, the results may be affected by recall bias and results cannot be used for causal inference.

\section{References}

1. Psaki, S., Z. A. Bhutta, T. Ahmed, S. Ahmed, P. Bessong, M. Islam, S. John, M. Kosek, A. Lima, C. Nesamvuni, P. Shrestha, E. Svensen, M. McGrath, S. Richard, J. Seidman, L. Caulfield, M. Miller, W.Checkley, and MALED Network Investigators , 2012. Household food access and child malnutrition: results from the eight-country MAL-ED study. Population Health Metrics, 10(24).

2. Asim, M. and Y. Nawaz, 2018. Child malnutrition in Pakistan: Evidence from Literature. MDPI, 5(60).

3. Legason, I. D. and R.Dricile, 2018. Prevalence of acute malnutrition among children ages 6-59 months: Results from a baseline nutrition survey in North-Western Uganda. Journal of Nutrition and Human Health, 2(1), 7-12.

4. Bangladesh Demographic and Health Survey (BDHS), 199697. NIPORT, Dhaka, Bangladesh; Mitra and Associates, Dhaka, Bangladesh.

5. Bangladesh Demographic and Health Survey (BDHS), 2014. NIPORT, Dhaka, Bangladesh; Mitra and Associates, Dhaka, Bangladesh.

6. World Health Organization (WHO), 2010. Nutrition Landscape Information System (NLIS): Country Profile Indicators Interpretation Guide.

7. World Urbanization Prospects: The 2014 Revision. United Nations, New York.

8. Fink, G., I. Gunther, and K. Hill, 2014. Slum residence and child health in developing countries. Demography, Springer, Population Association of America, 51(4), 1175-1197.

9. Smith, L. C., M.T. Ruel, and A.Ndiaye, 2005. Why is child malnutrition lower in urban than in rural areas? Evidence from 36 developing countries. World Development, 33(8), 1285-1305.

10. Srinivasan, S. C., G. Zanello, and B. Shankar, 2013. Ruralurban disparities in child nutrition in Bangladesh and Nepal. BMC Public Health, 13(581).

11. Bangladesh Urban Health Survey (UHS), 2013. NIPORT, Dhaka, Bangladesh.

12. Islam, A. and T. Biswas, 2015. Chronic stunting among under-5 children in Bangladesh: a situation analysis. Advances in Pediatric Research, 2(18).

13. Khan, R. E. A. and M. A. Raza, 2014. Nutritional status of children in Bangladesh: measuring CIAF and its determinants. Pakistan Journal of Commerce and Social Sciences, 8(1), 11-23.

14. Das, S. and J. Gulshan, 2017. Different forms of malnutrition among under five children in Bangladesh: a cross sectional study on prevalence and determinants. BMC Nutrition, $\mathbf{3 ( 1 )}$.

15. Talukder, A., 2017. Factors Associated with Malnutrition among Under-Five Children: Illustration using Bangladesh Demographic and Health Survey, 2014 Data. MDPI, 4(88).

16. Mansfield, E.R. and B.P. Helms, 1982. Detecting multicollinearity. The American Statistician, 36, 158-160.

17. Alison, P. D., 2001. Logistic Regression Using the SAS system: Theory and Applications, Cary, NC: SAS Institute Inc.

18. Midi, H., S. K. Sarkar, and S. Rana, 2010. Collinearity diagnostics of binary logistic regression model. Journal of Interdisciplinary Mathematics, 13(3), 253-267.

19. Gui, J. and H. Li, 2005. Penalized Cox regression analysis in the high-dimensional and low sample size settings, with applications to microarray gene expression data. Bioinformatics, 21, 3001-3008. 